\title{
Estimating On-Bottom Stability of Offshore Pipelines in Shallow Waters of the Gulf of Guinea
}

\author{
Ogbonda Douglas Chukwu ${ }^{1}$, Chinwuba Victor Ossia ${ }^{1}$, C. O. Akhigbemidu ${ }^{2}$ \\ ${ }^{1}$ Offshore Technology Institute, ETF Gas Engineering Building, University of Port Harcourt, Port Harcourt, Nigeria \\ ${ }^{2}$ Project Masters Nigeria Limited, East-West Road, Port Harcourt, Nigeria
}

Email address:

ossiacv@otiuniport.org (C. V. Ossia)

\section{To cite this article:}

Ogbonda Douglas Chukwu, Chinwuba Victor Ossia, C. O. Akhigbemidu. Estimating On-Bottom Stability of Offshore Pipelines in Shallow Waters of the Gulf of Guinea. International Journal of Mechanical Engineering and Applications. Vol. 4, No. 3, 2016, pp. 115-122. doi: 10.11648/j.ijmea.20160403.13

Received: May 14, 2016; Accepted: May 24, 2016; Published: June 13, 2016

\begin{abstract}
Pre-installation Stability analyses of pipelines are required to prevent lateral and upheaval buckling in service. In this study, the hydrodynamic forces associated with an offshore pipeline is analyzed, thereby determining limiting steel wallthickness and submerged weight necessary to prevent collapse and propagation buckling, contain pressure and ensure onbottom stability. Relevant design equations, Codes and Procedures were integrated to create a comprehensive platform for analyzing lift, drag and inertia forces acting on submerged pipelines. Hence, a user friendly template with multiple design settings has been developed with MathCAD ${ }^{\circledR}$ for on-bottom stability analyses. The analysis tool is based on the absolute lateral stability method in DNV RP F109. A case study of $\phi 762 \mathrm{~mm}$ x $34 \mathrm{~km}$ pipeline to be installed Offshore Escravos, Gulf of Guinea is simulated and analyzed using the design tool developed. Pipeline behavior under different environmental and pipeline conditions such as water depth, wave height, steel and concrete thickness were investigated. The results showed that concrete and steel wall thicknesses are the most critical parameters in the on-bottom stability of offshore pipelines. With a determined optimal wall thickness of $20.6 \mathrm{~mm}$, concrete thicknesses of $78.796 \mathrm{~mm}, 61.386 \mathrm{~mm}, 53.043 \mathrm{~mm}$ and $42.58 \mathrm{~mm}$ corresponding to $5 \mathrm{~m}, 10 \mathrm{~m}, 15 \mathrm{~m}$ and $20 \mathrm{~m}$ water depths, respectively were obtained. Also, the results showed that for pipes OD $>\phi 32.5$ in $(\phi 825.5 \mathrm{~mm})$ alternative stability methods may be required as the necessary concrete thickness may exceed allowable limits.
\end{abstract}

Keywords: Concrete Weight Coating, Concrete Coating Thickness, Pipeline Wall Thickness, On-Bottom Stability

\section{Introduction}

All submerged offshore pipelines and sections of onshore pipelines in swamps, floodable areas, high water table areas, river crossings etc., should be stable under the action of hydrostatic and hydrodynamic forces [1]. The hydrodynamic forces on the pipeline on the seabed are the combined action of wave and current. It is important to correctly predict these forces imposed on the pipeline since they have a direct impact on the safety and economy of any pipeline project [2].

Ensuring the on bottom stability of an offshore pipeline on the seabed is critical to that pipeline attaining and exceeding its design life. On-bottom stability of pipelines is governed by the fundamental balance between loads and resistances. In offshore pipelines, these loads are hydrodynamic loads induced by waves and currents. This load-resistance relationship has formed the basis for various design codes governing the stability of submarine pipelines such as the API RP 1111 [3], DNV RP E305 [4], DNV RP F109 [5], and DNV OS F101 [6].

Ensuring the stability of offshore pipelines involves maintaining lateral stability (preventing the pipeline from sliding sideways) and vertical stability (the pipeline being stable on the seabed or buried). Predicting on-bottom pipeline stability is complex requiring interdisciplinary integration including; soil constitutive modeling, seabed liquefaction, scour and sediment transport, structural mechanics and prediction of ocean waves and hydrodynamic loads. Considering this complexity, most pipelines are designed using very simplified models [7].

The most common practice to achieve on bottom stability 
onshore is by application of sufficient concrete coating to counteract buoyancy forces as it would not be economical to increase steel wall thickness to a level that sufficiently weighs down the pipeline. However in offshore pipelines, there are practical limits to which concrete coating can be applied as heavy pipelines imply high installation stresses on the lay vessel and on the pipe itself. In the 1970s, the Coulomb theory of soil friction was used to gauge soil resistance to the displacement of submarine pipelines under hydrodynamic loads such as waves and ocean currents [8]. This model adopts a load-resistance relationship that ensures the pipe does not displace horizontally i.e. hydrodynamic loading must not exceed pipe and soil resistance. The DNV-RP-F109 [5] which reflects state-of-the-art industry practice and latest research, also utilizes the Load and Resistance Factors Design Format (LRFD). This method places an upper (allowable) limit on pipe displacement due to hydrodynamic loads, with target safety levels given in the DNV-OS-F101 [6].

The DNV-OS-F101 [6] presents a force balance method where a subsea pipeline has been considered stable if it has got sufficient submerged weight so that the lateral soil resistance is sufficiently high to restrain the pipeline from deflecting sideways. The main stabilizing method has traditionally been to apply sufficient amount of concrete weight coating (CWC). The traditional design approach for subsea pipelines which is expressed in the early design codes, such as "Rules for Submarine Pipeline Systems" [9], was to not to allow for any horizontal movement when a pipe is exposed to the environmental conditions associated with an extreme return period, i.e., a 100 year Return Period. Even if this method has been widely replaced by the empirical or calibrated methods, the force balance method is still in common use in cases where a pipeline is exposed to pure current [10].

The design method presented in the DNV-RP-E305 [4] relates to a pipeline resting on the seabed throughout its lifetime, or prior to some other form of stabilization (e.g. trenching, burial, self-burial). The stability of the pipeline is then directly related to the submerged weight of the pipeline, the environmental forces and the resistance developed by the seabed soil. Consequently, the aim of stability design is to verify that the submerged weight of the pipeline is sufficient to meet the required stability criteria. Three different analysis methods were used in this code. The Dynamic Stability Analysis method and two simplified or calibrated methods that do not require full dynamic FE analysis, namely, the Simplified and General Stability Analysis methods. The Dynamic Stability Design Method is based on a time-domain solution of the pipeline stability and incorporates three-dimensional effects, surface wave spectra and nonlinear soil resistance.

The Generalized method comprises a set of design response curves which have been developed based on a large number of dynamic FE simulations. The background for the methodology is based on the assumption that the pipeline lateral displacement is to a large extent a function of a relative small number of non-dimensional parameters. The curves for use in sandy soils are for net pipe movements of up to 40 pipe diameters in DNV Zone 1 (more than $500 \mathrm{~m}$ away from a platform) or $0 \mathrm{~m}$ in DNV Zone 2 (less than $500 \mathrm{~m}$ from a platform). No displacement is allowed in clays. The curves are based on pipe roughness and sea state spectrum (JONSWAP), which helps determine the wave-induced velocity.

DNV recommends the Simplified Stability Design Method based on a link between the traditional stability design procedure and the generalized stability analysis. The results from the two distinct methods are made consistent with each other through the use of two calibration factors: one based on the soil conditions, and one based on the Keulegan-Carpenter number and ratio of wave to current velocity. The calibration factors ensure that the results of the simplified analysis tie in with the generalized analysis [11].

A calibration factor is multiplied by the submerged weight determined from the traditional type design to arrive at the new design submerged weight. The factor varies from 1.0 to 1.6. The calibration gives pipe weights that produce a conservative envelope to the generalized procedure. For this method, simplified design is characterized as;

- a hydrodynamic force (Morison type) formulation with force coefficients $0.7,0.9$, and 3.29 for $C_{D}, C_{L}$, and $C_{M}$ respectively and,

- a simple frictional soil resistance model with coefficients of 0.7 for sand and 0.15 to 1.3 for clays.

The wave induced water particle velocity is taken as the significant bottom velocity. This deviates from traditional designs where the wave induced water velocity is normally taken as that associated with the significant wave or sometimes the maximum wave. This analysis is again based on pipelines designed with an allowable lateral displacement of up to $20 \mathrm{~m}$ in sandy soil and $0 \mathrm{~m}$ in clayey soil. As a result of extensive research and developments performed in the 1980s in the area of pipeline stability, it was accepted that some movement can be allowed during extreme sea states provided that the lateral displacements were kept within defined limits. This is reflected in the two calibrated methods, the Simplified and the Generalized Methods, which do not require Finite Element analyses. The limitations of this code include:

- The code does not provide guidance on pipe-seabed interaction forces for pipelines on carbonate soils;

- It does not allow for the effect of pipeline embedment on soil resistance and hydrodynamic loading; and

- It does not consider the effects of seabed instability within the response of the pipeline during storm loading [12].

This code has been replaced by the new DNV-RP-F109.

The DNV-RP-F109 was first published in 2007 and updated in 2010, and it has superseded the old DNV-RPE305. This updated code does allow for some effects of pipeline embedment. However, it does not consider asymmetrical embedment levels, and also does not provide quantitative guidance for carbonate soils. Three stability analysis methods are included in this code. The Absolute Lateral Static Stability method of the DNV-RP-F109 replaces the force balance method of the DNV-OS-F101 [13] and the simplified method of the DNV-RP-E305. It ensures that no pipe motion will occur when the pipeline is exposed to 
maximum load during sea state. This method appears to be significantly more conservative than the more traditional force balance method. In most situations, some minor pipe movements $(<1 \mathrm{~m})$ can safely be allowed which will significantly reduce the required pipeline submerged weight [10]. As this method has evolved, the criteria for defining pipeline stability have loosened and now extend to allowing the pipeline to displace a significant predefined lateral distance under a given load condition. This allowance leads to the next two types of stability analysis methods [15].

The Generalized Lateral Stability Method of the DNV-RPF109 as opposed to the E305 which presented curves for lateral displacements ranging from 0 to 40 times the external pipe diameter. The new design code, F109 is based on a lateral displacement limited to up to 10 pipe diameters during a given sea state. But it follows similar design principles as the respective method in E305.

The Dynamic Lateral Stability Analysis method is used to predict the displacement of a pipeline during a design storm event. Although the use of dynamic FE analyses to calculate pipeline structural response is the most comprehensive method available to assess pipeline stability, the method has not been widely used by pipeline engineers for several reasons. Firstly, in many locations around the world where stability can readily be mitigated by applying a minimal amount of Concrete Weight Coating (CWC), there has not been a strong motivation for replacing the calibrated (Simplified and Generalized) methods with a more advanced FE-based method. Secondly, the design tools based on this method are not easily available [10]. The limitations of the DNV-RP-F109 are as follows:

- This code focuses on pipeline on-bottom stability with relatively low embedment levels, and is not suited to the assessment of highly embedded pipeline sections,

- This updated code allows for some effects of pipeline embedment; however it does not consider asymmetrical embedment levels, and also does not provide quantitative guidance for carbonate soils,

- It does not consider the effects of the changes in seabed bathymetry (seabed topography) during a storm event on pipeline stability [12].

Three design procedures (Levels 1, 2 and 3) are presented in AGA design guidelines and software [14]. The first procedure (Level 1) is based on traditional stability analysis methods (Morison type hydrodynamic forces and frictional soil resistance). It is intended only as a reference to the type of static analysis which has been done in the past. The most detailed procedure uses finite element time domain simulation software (Level 3). The software provides detailed information regarding pipe movement and stresses during design events. Pipeline safety is then assessed based on these results.

The Level 2 procedure assumes no net movement of the pipe, and is based on a quasi-static calculation which simulates the embedment process modeled in the Level 3 software. The process modeled is that of a pipe embedding itself into the soil during small amplitude displacement oscillations caused by wave loadings. The resulting lateral soil resistance is calculated and compared to the expected hydrodynamic forces to determine pipe stability. Levels 2 and 3 allow a much better representation of the sea state than the "design wave" approach used in Level 1 [16]. The limitations of AGA include:

- The AGA design code does not allow pipeline displacement;

- The AGA hydrodynamic model is not based on field measurement data, it's based solely on laboratory model tests;

- The AGA design code does not assume a design sea spectrum, but allows the user to specify the sea state representation.

Some similarities exist between the AGA method and the DNV-RP-F109's method:

a) Both methods are based on very similar dynamic simulation tools which use a FE pipeline model subject to irregular waves plus steady current loadings.

b) Both methods include history dependent pipe-soil interaction models, where soil resistance and pipe embedment are based on recent pipe movement history.

c) Both are based on the assumption that the duration of the design sea-state is 3 hours;

d) The hydrodynamic force formulations are quite different between the two design tools. The resulting forces produced by both models are very similar though. This demonstrates the accuracy of the hydrodynamic forces estimation.

The analysis methods in DNV-RP-F109 range from an absolute stability where no movement of the pipeline is allowed to a lateral displacement of up to 10 pipe diameters. This range makes it a very versatile and flexible standard which can be used for different types of purposes to which the pipeline is intended. For the on-bottom stability analysis procedures, it can be seen that, the DNV standard, which is based on empirical design parameters, has a very detailed approach compared to all other codes and standards. Besides, DNV standard is regarded as a well-respected code to which the majority of the other standards refer. Therefore, the design procedures and sensitivity analyses in this work are based on the state-of-the-art DNV-RP-F109 standard.

\section{Methodology}

\subsection{Input Data}

Data for this research was obtained from a pipeline scheduled for installation at Offshore Escravos Oilfield in the Niger Delta region. The data input for this study can be categorized into pipeline properties, environmental data and seabed properties.

The input data for pipelines properties of this study include: Pipeline Wall Thickness $t(\mathrm{~mm})=20.6$ (calculated); Corrosion Coating Thickness $t_{c c}(\mathrm{~mm})=5$; Density of Steel Material $\rho_{s t}\left(\mathrm{~kg} / \mathrm{m}^{3}\right)=7850$; Nominal Outer Diameter of Steel $D_{o}(\mathrm{~mm})=30$; Density of Corrosion Coating $\rho_{c c}$ $\left(\mathrm{kg} / \mathrm{m}^{3}\right)=1300$ (Single Layer FBE corrosion coating); 
Density of Concrete Coating $\rho_{c}\left(\mathrm{~kg} / \mathrm{m}^{3}\right)=3044$; Density of Seawater $\rho_{w}\left(\mathrm{~kg} / \mathrm{m}^{3}\right)=1025$; Density of Field Joint Filler coating $\rho_{f j}\left(\mathrm{~kg} / \mathrm{m}^{3}\right)=1026$ (PUF - Polyurethane field joint) when submerged); Joint Length $L_{\text {pipe }}(\mathrm{m})=12.19$; Concrete Cut-Back Length $L_{f j}(\mathrm{~mm})=355.6$. The density of pipeline contents $\rho_{i}\left(\mathrm{~kg} / \mathrm{m}^{3}\right)=0$ for Cases $1-4$ (installation stage) and 855.691 for case-5 (pipeline operational stage - with oil and gas); while the Concrete Coating Thickness $t_{c}(\mathrm{~mm})$ specified by client was $82.55,76.2,63.50$ and 82.55 for Case-1, 2, 3, 4 and 5 , respectively.

Relevant environmental data utilized in this study include: Reduction due to wave spreading and directionality, $\mathrm{R}=1$; Reference height above seabed $z_{r}(\mathrm{~m})=0.9144$; Angle of shallow wave with pipeline $\theta_{l}\left(^{\circ}\right)=60$; Concrete Water Absorption $\xi(\%)=4$; Current Velocity at reference height $U_{\text {ref }}$ $(\mathrm{m} / \mathrm{s})=0.1542$; Phase angle of the hydrodynamic force in the wave cycle $\theta\left(^{\circ}\right)=0.360$; Inertia Force Coefficient $C_{M}=3.29$; Lift Force Coefficient $C_{L}=0.9$; Kinematic Viscosity $v\left(\mathrm{~m}^{2} / \mathrm{s}\right)=$ $1.03^{\times} 10^{-6}$; Current direction w.r.t. pipeline $\theta_{\text {curr }}\left({ }^{\circ}\right)=90$; Slope of trench $\theta_{\text {slope }}(\mathrm{deg})=30,0,0,0$ and 30 for case-1,2, 3, 4 and case-5, respectively. Similarly, the pipeline burial depth $\mathrm{H}(\mathrm{m})$ $=2,0,0,0$, and 2 for case-1, 2, 3, 4 and case-5, respectively. Wave Spectral Peak Period $T_{p}(\mathrm{~s})=16.6 \mathrm{~s}$ for cases 1, 2, 3, 4, and 17.9 for case-5. Water depth $\mathrm{d}(\mathrm{m})=4,10,15,20$ and 5 for case 1, 2, 3, 4 and case 5, respectively; whereas the significant wave height $\mathrm{H}_{\mathrm{s}}(\mathrm{m})=2.262,2.505,2.804,2.716$ and 2.862 for case 1, 2, 3, 4 and case 5, respectively.

Seabed grain size $d_{50}$ and the undrained shear strength of soil $S_{u}$ for Cases $1-5$ were $0.0625 \mathrm{~mm}$ and $224.338 \mathrm{~kg} / \mathrm{m}^{2}$ (2.2in), respectively.

\subsection{Design Assumptions for the Template Development}

- No marine growth on the pipeline was considered.

- Current and waves acting perpendicular to the pipeline.

- Water Absorption as a percentage of concrete weight was taken as $4 \%$.

- The soil friction factor for the seabed is calculated based on DNV-RP-E305 [4].

- The 10 year significant wave height and peak period plus 1 year current are considered for the installation condition. Pipeline is assumed to be empty for all installation cases.

- The 100 year significant wave height and peak period plus the 10 year current are considered for the operating conditions (Case 5). Minimum internal product density of $860 \mathrm{~kg} . \mathrm{m}^{-3}$ has been used.

\subsection{Procedures / Algorithms}

The following procedures leading to algorithm equations (1) - (15) were adhered to in this study:

- The submerged weight of the pipeline in air and with product taking buoyancy into consideration was calculated using the algorithm;

$W_{s}=W_{s a}+W_{i}+\frac{A_{C}}{L_{j o i n t}} \cdot\left(2 \cdot L_{f j} \cdot \rho_{f j}\right)+\xi \cdot A_{c} \cdot \frac{L_{j o i n t}-2 \cdot L_{f j}}{L_{j o i n t}} \cdot \rho_{c}-B$

- The corresponding significant water velocity was interpolated from the Pierson Moskovitz curve [17] for corresponding values of wave height $H_{s}$ and $T_{n} / T_{p}$ ratio using the algorithm:

$$
U_{s S}=\frac{H_{s}}{T_{n}} \cdot \operatorname{linterp}\left\{\operatorname{TnbTp}, P M, \frac{T_{n}}{T_{p}}\right\}
$$

- The zero up crossing period corresponding to the $T_{n} / T_{p}$ ratio was obtained using the algorithm:

$$
T_{u}=T_{p} \cdot \operatorname{linterp}\left\{\operatorname{TnbTp}, T u T p, \frac{T_{n}}{T_{p}}\right\}
$$

In obtaining the calibration factor $F_{w}$ as a function of keulegan carpenter number $\mathrm{K}$ and current to wave ratio $\mathrm{M}$, the graphs from DNV-RP-E305 [4] for calibration factor was transformed into a nested if statement below.

For $\mathrm{M} \leq 0.2$

$F_{w}=$ if $[K \leq 5,1.0$, if $[K \geq 25,1.6,0.03 \cdot(K-5)+1]]$

For $0.2<\mathrm{M}<0.4$

$$
F_{w}=\text { if }[K \leq 5,1.0, \text { if }[K \geq 21.6,1.5,0.03 \cdot(K-5)+1]]
$$

For $0.4 \leq \mathrm{M} \leq 0.6$

$$
F_{w}=\text { if }[K \leq 5,1.0, \text { if }[K \geq 18.3,1.4,0.03 \cdot(K-5)+1]]
$$

For $0.6<\mathrm{M}<0.8$

$$
F_{w}=\text { if }[K \leq 5,1.0, \text { if }[K \geq 15.3,1.3,0.03 \cdot(K-5)+1]]
$$

Otherwise,

$F_{w}=$ if $[K \leq 5,1.0$, if $[K \geq 12,1.2,0.03 \cdot(K-5)+1]](8)$

- The Lift $F_{L}$, Drag $F_{D}$ and Inertia forces $F_{I}$ acting on the pipeline as a function of phase angle was calculated using Morison's equation. Considering lift and drag trench reduction factors, the algorithm took the form:

$$
\begin{gathered}
F_{L}(\theta)=\frac{1}{2} \cdot f_{r l} \cdot \rho_{w} \cdot D \cdot C_{L} \cdot\left(U_{s} \cdot \cos \theta+U_{c}\right)^{2}(9) \\
F_{D}(\theta)=\frac{1}{2} \cdot f_{r x} \cdot \rho_{w} \cdot D \cdot C_{D} \cdot\left|\left(U_{s} \cdot \cos \theta+U_{c}\right)\right|\left(U_{s} \cdot \cos \theta+U_{c}\right)(10) \\
F_{I}(\theta)=\frac{\pi \cdot D^{2}}{4} \cdot \rho_{w} \cdot C_{M} \cdot A_{s} \cdot \sin \theta
\end{gathered}
$$

For sections of the pipeline that are unburied, the lift and drag trench reduction factors, $\mathrm{f}_{\mathrm{rl}}$ and $\mathrm{f}_{\mathrm{rx}}$, do not apply.

- Citing Sec. 5.3.6 of DNV-RP-E305, the limiting value of submerged weight, $\mathrm{W}_{\text {smin }}$, as a function of phase angle, $\theta$, was calculated using:

$$
W_{\text {smin }}(\theta)=\left[\frac{\left(F_{D}(\theta)+F_{I}(\theta)\right)+\mu \cdot F_{L}(\theta)}{\mu}\right] \cdot F_{w}
$$

The required minimum submerged weight to ensure lateral stability, $\mathrm{W}_{\text {subreq, }}$ is given as the maximum limiting value of submerged weight over a wave cycle. This value is obtained through using MathCad command by Mathsoft [18]:

$$
W_{\text {subreq }}=\max \left(W_{\text {smin }}(\theta)\right)
$$


- To find the required area of concrete coating, $\mathrm{A}_{\mathrm{c}_{-} \text {req }}$, iteration was carried out in MathCad to find the area of concrete coating that satisfies the condition:

$$
\begin{gathered}
W_{\text {subreq }}=A_{s t} \cdot \rho_{s t}+A_{c c} \cdot \rho_{c c} \\
+\frac{A_{c}}{L_{\text {joint }}}\left[\left(L_{\text {joint }}-2 \cdot L_{f j}\right) \cdot \rho_{c}\right]+W_{i}+\frac{A_{c}}{L_{\text {joint }}}\left(2 \cdot L_{f j} \cdot \rho_{f j}\right) \\
+\xi \cdot A_{c} \cdot \frac{L_{\text {joint }}-2 \cdot L_{f j}}{L_{\text {joint }}} \cdot \rho_{c}-\rho_{w}\left(A_{c}+\frac{\pi \cdot D_{c c}^{2}}{4}\right)
\end{gathered}
$$

- To find the required concrete coating thickness, $\mathrm{t}_{\mathrm{c} \_ \text {req, }}$, iteration was carried out in MathCad to find the concrete coating thickness that satisfied the condition:

$$
A_{c_{-} r e q}=\pi \cdot\left(D_{c c} \cdot t_{c_{-} r e q}+t_{c_{-} r e q}^{2}\right)
$$

\section{Results and Discussions}

The primary objective of pipeline design it to optimize the relationship between pipe diameter, pipe material, pipe wall thickness, appurtenances, economics, constructability and operability of the pipeline. Raw input data (from section 2.1) were inputted into the Mathcad template created in sections 2.2 and 2.3 above.

\subsection{Hydrodynamic Forces}

Figure 1 shows that for the $5 \mathrm{~m}$ water depth installation case, the maximum lift, drag and inertia forces for one complete wave cycle were $333.291 \mathrm{~N} / \mathrm{m}, 518.453 \mathrm{~N} / \mathrm{m}$ and 1495.392 $\mathrm{N} / \mathrm{m}$, respectively. Ghebreghiorghis [7] stated that there is a phase difference of $90^{\circ}$ between the maximum water particle velocity and acceleration and that the maximum lift and drag forces occur when the inertia force is zero, while the maximum inertia force occurs at minimum lift force. This interrelationship between the hydrodynamic loads is corroborated by the results in Figure 1. The hydrodynamic forces are sine and cosine functions, drag and inertia forces can be positive or negative depending on the direction of motion, that is, left or right. But as observed from Figure 1 the lift force consists of only positive values (does not go below zero), owing to lift force being a one way upwards force.

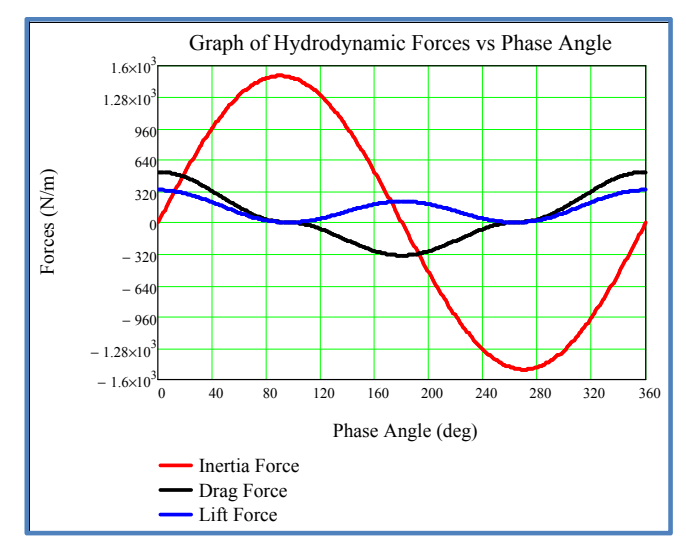

Figure 1. Hydrodynamic forces versus phase angle (Case 1).

It can be observed from Figure 2 that the lift, drag and inertia forces acting on the pipeline are generally observed to decrease as the water depth increases. However, there was an observed increase in lift force from the $5 \mathrm{~m}$ to the $10 \mathrm{~m}$ water depth region. The reduction in hydrodynamic forces with water depth is due to the increase in wavelength and reduction in water particle kinematics as depth increases. For case 5 (Figure 2) there is a significant increase in inertia force when compared to case 1 . This is because as the pipe is with product (oil + water + gas) there is an increased resistance to motion.

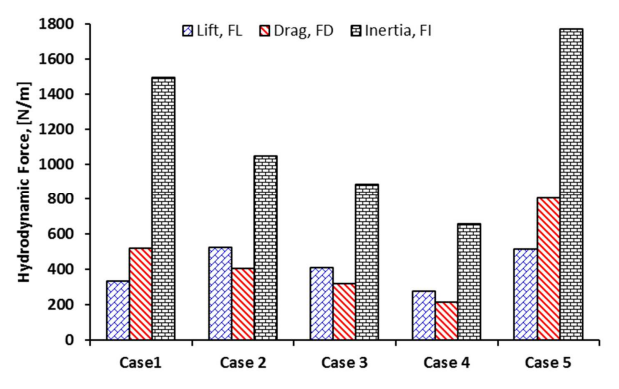

Figure 2. Maximum hydrodynamic forces.

\subsection{Submerged Weight and Buoyancy}

The counteracting buoyancy imposed on a pipeline by the surrounding seawater are functions of the total outer diameter of the pipeline, that is, OD considering diameter of pipe, concrete coating (if any), marine growth (if any). The inherent submerged weight of the pipeline is however a function of the weight of the pipe, the weight of the concrete coating, the weight of the field joint coating and the weight of the internal fluid taking into cognizance the buoyant force.

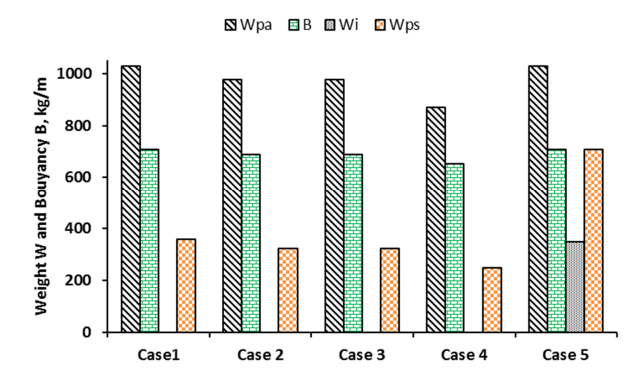

Figure 3. Weight and buoyancy variations for Cases 1-5.

These factors are evident in Figure 3 as the buoyancy remains almost constant from case 1 through case 5 owing to the negligible variation in coating thicknesses. The weight of the coated pipe in air also reduces slightly from cases 1 through 4 due to concrete coating reduction. The submerged weight however is maximum in case 5 as the pipe is now with product.

\subsection{Wave, Current and Stability Parameters}

Table 1 shows the response of wave and current parameters (such as the significant water velocity, $\mathrm{U}_{\mathrm{s}}$, the zero-up crossing period, $\mathrm{T}_{\mathrm{u}}$, average velocity acting over the pipe OD, significant acceleration perpendicular to the pipeline, $\mathrm{A}_{\mathrm{s}}$, and the boundary layer reduction factor, $(\mathrm{BRF})$ to changes in water depth. Table 2 shows the behavior of the stability parameters such as the soil friction factor, M, Keulegan Carpenter number, 
$\mathrm{K}$, Current to wave ratio, $\mathrm{M}$, and the calibration factor, $\mathrm{F}_{\mathrm{w}}$, with respect to changes in water depth.

\subsection{Stability Requirements / Analysis}

The minimum required submerged weight (maximum required weight over a wave cycle) is as shown in Figure 4, and the required concrete coating size thickness was found to be $336.42 \mathrm{~kg} / \mathrm{m}$ and $78.796 \mathrm{~mm}$, respectively. Preliminary concrete sizing as specified in the design basis for the case study proved to be sufficient to ensure on-bottom stability for both the installation and operational cases.

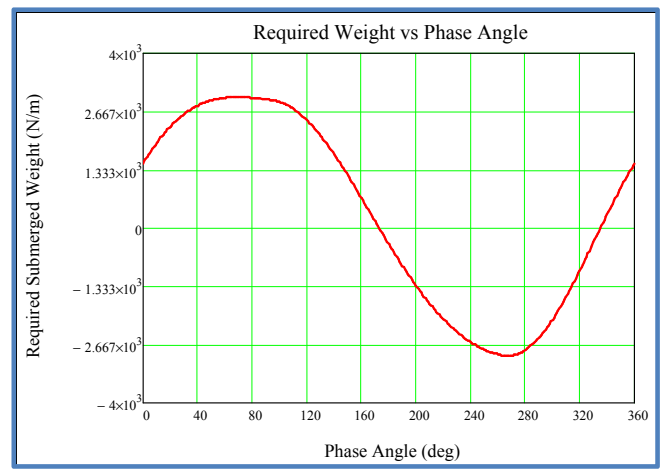

Figure 4. Required submerged weight over a wave cycle (Case 1).

Figure 5 showed the stability requirements; minimum required submerged weight of the pipeline, minimum required concrete coating area and the minimum required concrete coating thickness, for the 5 load cases. The $5 \mathrm{~m}$ water depth scenario was found to be the critical condition as the concrete coating thickness required to ensure stability was maximum at this water depth. When considering the operational condition for the $5 \mathrm{~m}$ water depth scenario, the required submerged weight was discovered to be higher than what was determined for the installation case. However, as the pipe is with product, the concrete coating thickness required to achieve said submerged was smaller than for the installation case.

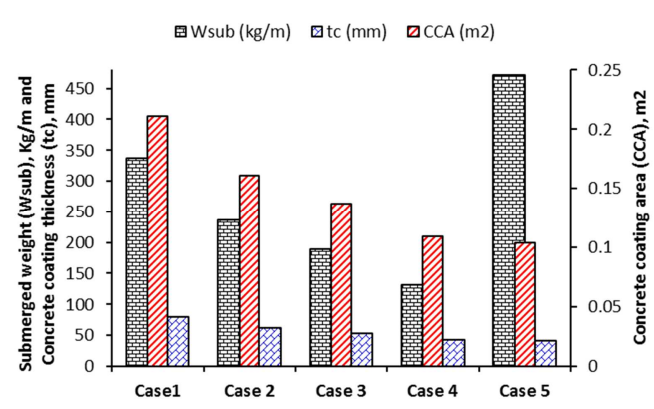

Figure 5. Minimum stability requirements.

The reduction in magnitude of stability requirements as water depth increases as shown in Figure 5 is due to the reduced effect of hydrodynamic forces on the pipeline (section 3.1). Increase in wavelength, reduction in water particle kinematics, and negligible wave velocity at seabed level result in reduced forces on the pipeline meaning a lesser submerged weight is required to negate said forces. The parameter being varied, concrete coating thickness, to achieve the required submerged weight is therefore reduced. This reduction continues deeper offshore till the pipe can be laid bare (without concrete coating) on the sea floor and still remain hydrodynamically stable.

Table 1. Wave and Current parameters calculation.

\begin{tabular}{|c|c|c|c|c|c|}
\hline Parameter & Case1 & Case 2 & Case 3 & Case 4 & Case 5 \\
\hline Time parameter $T_{n}(s)$ & 0.714 & 1.010 & 1.237 & 1.428 & 0.714 \\
\hline Significant water velocity $U_{s}(\mathrm{~m} / \mathrm{s})$ & 1.292 & 0.964 & 0.838 & 0.673 & 1.641 \\
\hline Zero-Up Crossing Period $\mathrm{T}_{\mathrm{u}}(\mathrm{s})$ & 12.634 & 13.101 & 13.482 & 13.803 & 13.543 \\
\hline Average velocity acting over the pipeline $U_{D}(\mathrm{~m} / \mathrm{s})$ & 0.142 & 0.142 & 0.142 & 0.141 & 0.142 \\
\hline Significant Acceleration Perpendicular to Pipeline $A_{s}\left(m / s^{2}\right)$ & 0.6423 & 0.4623 & 0.3905 & 0.3062 & 0.7615 \\
\hline Boundary layer reduction factor $\mathrm{B}_{\mathrm{RF}}$ & 0.919 & 0.918 & 0.918 & 0.916 & 0.919 \\
\hline
\end{tabular}

Table 2. Stability parameters.

\begin{tabular}{llllll}
\hline Parameter & Case1 & Case 2 & Case 3 & Case 4 & Case 5 \\
\hline Soil Friction Factor M & 0.7 & 0.7 & 0.7 & 0.7 & 0.7 \\
Keulegan Carpenter Number K & 17.412 & 13.66 & 12.222 & 10.327 & 23.723 \\
Current - Wave Velocity Ratio M & 0.11 & 0.147 & 0.169 & 0.21 & 0.086 \\
Calibration Factor F $\mathrm{F}_{\mathrm{w}}$ & 1.372 & 1.26 & 1.217 & 1.16 & 1.562 \\
\hline
\end{tabular}

Table 3. Parametric analysis results.

\begin{tabular}{|c|c|c|c|c|c|}
\hline Parameter & $D=20 \mathrm{in}$ & $D=25 i n$ & $D=30$ in & $\mathrm{D}=\mathbf{3 5}$ in & $D=40 \mathrm{in}$ \\
\hline Wall Thickness t (mm) & 14.3 & 17.5 & 20.6 & 23.8 & 27 \\
\hline Maximum Lift Force $F_{\text {Lmax }}(\mathrm{N} / \mathrm{m})$ & 241.586 & 287.375 & 333.291 & 379.318 & 425.442 \\
\hline Maximum Drag Force $F_{D \max }(\mathrm{N} / \mathrm{m})$ & 375.801 & 447.027 & 518.453 & 590.05 & 661.798 \\
\hline Maximum Inertia Force $F_{\operatorname{Imax}}(\mathrm{N} / \mathrm{m})$ & 794.606 & 1118 & 1495 & 1928 & 2416 \\
\hline Buoyancy B (kg/m) & 376.016 & 528.828 & 707.635 & 912.435 & 1143 \\
\hline Submerged Weight $\mathrm{W}_{\mathrm{s}}(\mathrm{kg} / \mathrm{m})$ & 282.175 & 324.505 & 358.601 & 387.722 & 410.388 \\
\hline Required Submerged Weight $\mathrm{W}_{\text {subreq }}(\mathrm{kg} / \mathrm{m})$ & 215.535 & 271.031 & 336.42 & 410.867 & 493.569 \\
\hline Required Concrete Coating Thickness $\mathrm{t}_{\mathrm{c} \_ \text {req }}(\mathrm{mm})$ & 66.773 & 71.984 & 78.796 & 85.975 & 93.482 \\
\hline Lateral Stability, Check stab & Adequate & Adequate & Adequate & Inadequate & Inadequate \\
\hline
\end{tabular}




\subsection{Parametric Analysis}

Pipeline outer diameter is one of the main factors affecting the submerged weight required to ensure stability to a great extent. Pipeline diameter does not directly affect water particle velocities but it affects hydrodynamic forces directly [7].

A parametric analysis was performed using input parameters for case 1, keeping all other parameter constant while varying pipe outer diameter and wall thickness. The buoyancy, lift, drag and inertia forces, as shown in Table 3, were seen to increase as pipeline diameter was increased from OD 20 inches to OD 40 inches. Figure 6 shows the variation in the pipeline inherent submerged weight and the required submerged weight to ensure stability as the pipe outer diameter is increased. The graph shows that for pipeline OD $>32.5$ in $(825.5 \mathrm{~mm})$, the required concrete coating thickness of 78.796 $\mathrm{mm}$ becomes insufficient for lateral stability.

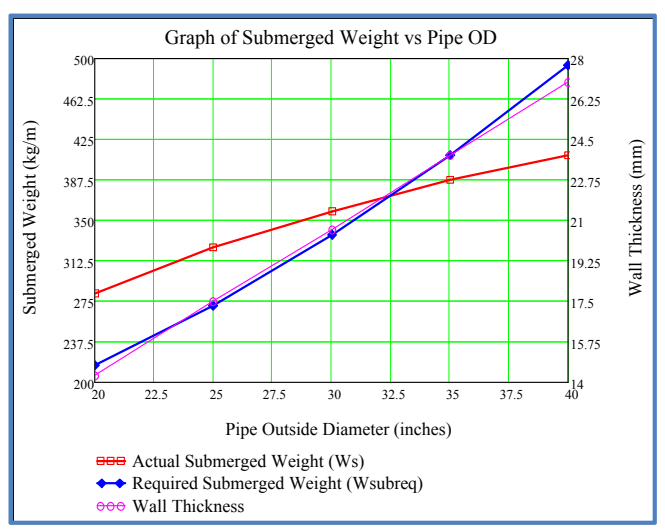

Figure 6. Submerged weight versus pipe outer diameter.

It is recommended that pipelines to be installed offshore be further segmented, that is, readings for environmental data be taken at steps of $2 \mathrm{~m}$ water depth. This will further optimize sizing done for concrete coating requirements reducing project cost. Corrosion and marine growth rates should be forecasted to evaluate the stability of the pipeline after years of operation. Dynamic simulation of the pipeline on the seabed considering waves and currents should be carried out to further verify its stability. Drag and Inertia coefficients, $C_{D}$ and $C_{M}$, have been known to vary with relative clearance as shown in experiments performed by Jothi-shankar and Sundar, [19]. Therefore, further work should be done varying coefficient values accordingly and their effects on submerged weight.

From the stability checks it was observed that all five Cases $1-5$ exhibited ADEQUATE vertical stability and lateral stability.

\section{Conclusion}

The sections of the pipeline near shore required a greater concrete coating thickness due to increased drag, lift and inertia forces from hydrodynamic activity as seen in Figure 5. The effect of hydrodynamic forces on pipelines on the seabed reduces with water depth as shown in Figure 2. The design template successfully verified the sufficiency of preliminary concrete coating sizing performed on AGA software. The submerged weight of the pipeline (using the specified concrete thicknesses in the design basis) ensures lateral stability by surpassing the required submerged weight by a factor of at least 1.1. Pipeline outer diameter affects the onbottom stability of submarine pipelines to a great extent. A concrete coating thickness of $82.55 \mathrm{~mm}$ proved to be inadequate to ensure on bottom stability for pipelines OD > $\phi 32.5$ in $(\phi 825.5 \mathrm{~mm})$ installed at $5 \mathrm{~m}$ water depth. For pipelines exceeding this nominal diameter, other methods of weighting such as rock dumping and concrete mats be considered over increasing concrete coating thickness. As further concrete coating thickness increase may induce excessive installation stresses.

\section{Nomenclature}

DNV Den Norske Veritas

AGA American Gas Association

API American Petroleum Institute

LRFD Load \& Resistance Factors Design Format

CWC concrete weight coating

Uss Significant Water velocity

$D_{o} \quad$ Nominal Outer Diameter of Steel

$t \quad$ Pipeline Wall Thickness

$t_{c c} \quad$ Corrosion Coating Thickness

$t_{c} \quad$ Concrete Coating Thickness

$\rho_{s t} \quad$ Density of Steel Material

$\rho_{c c} \quad$ Density of Corrosion Coating

$\rho_{c} \quad$ Density of Concrete Coating

$\rho_{w} \quad$ Density of Seawater

$\rho_{i} \quad$ Density of Pipeline Contents

$\rho_{f j} \quad$ Density of Field Joint Filler

$L_{\text {pipe }} \quad$ Joint Length

$L_{f i} \quad$ Concrete Cut-Back Length

$D \quad$ Water Depth

$H_{s} \quad$ Significant Wave Height

$T_{p} \quad$ Spectral Peak Period

$\theta_{I}\left({ }^{\circ}\right) \quad$ Angle of shallow wave with pipeline

$U_{\text {ref }} \quad$ Current Velocity at reference height

$\theta_{\text {curr }} \quad$ Current direction w.r.t. pipeline

$\mathrm{R} \quad$ Reduction due to wave spreading and directionality,

V Kinematic Viscosity

$C_{L} \quad$ Lift Force Coefficient

$H \quad$ Depth of burial

$\theta_{\text {slope }} \quad$ Slope of trench

$C_{M} \quad$ Inertia Force Coefficient

$z_{r} \quad$ Reference height above seabed

$\xi \quad$ Water Absorption percentage of concrete

$\theta \quad$ Hydrodynamic force Phase angle

$d_{50} \quad$ Seabed grain size

$S_{u} \quad$ Undrained shear strength of soil

$\mathrm{F}_{\mathrm{w}} \quad$ calibration factor

$\mathrm{K} \quad$ keulegan carpenter number

$\mathrm{M} \quad$ current to wave ratio 


\section{References}

[1] Gong, S. W., Lam, K. Y., Lu, C., (2000). Structural Analysis of a Submarine Pipeline Subjected to Underwater Shock. International Journal of Pressure Vessels and Piping, 77.

[2] Mohd. Ridza, B. H., (2007), On-Bottom Stability Analysis and Design of Submarine Pipelines, Faculty of Civil Engineering, University of Technology Malaysia.

[3] American Petroleum Institute (API), (1999). Design, Construction, Operation and Maintenance of Offshore Hydrocarbon Pipelines - Limit State Design (RP 1111). API Publishing Services, Washington, D.C.

[4] Det Norske Veritas (DNV), (1988). On-Bottom Stability Design of Submarine Pipelines (RP E305). Veritas Offshore Technology and Services A/S.

[5] Det Norske Veritas (DNV), (2010). On-Bottom Stability Design of Submarine Pipelines (RP F109). Det Norske Veritas AS.

[6] Det Norske Veritas (DNV) (2013); Submarine Pipeline Systems (OS F101). Det Norske Veritas AS.

[7] Ghebreghiorghis, D. A., (2014). On-Bottom Stability Analysis of Subsea Pipelines according to DNV-RP-F109, Faculty of Science and Technology, University of Stavanger.

[8] Murthy, V. N. S., (2002), Geotechnical Engineering Principles and Practices of Soil Mechanics and Foundation Engineering, CRC Press, New York.

[9] Det Norske Veritas (DNV) (1981); "Rules for submarine pipeline systems", Det Norske Veritas AS, April 1981.

[10] Tornes, K., Cumming, G., Zeitoun, H., and Willcocks, J., (2009), A Stability Design Rationale - A Review of Present Design Approaches, Proceedings of the ASME $28^{\text {th }}$
International Conference on Ocean, Offshore and Arctic Engineering, 2009.

[11] Palmer, A. C., and King, R. A., (2008), Subsea Pipeline Engineering, PennWell Corporation, Oklahoma, USA.

[12] Jas, E., O'Brien, D., Fricke, R., Gillen, A., Cheng, L., White, D., and Palmer, A., (2012). Pipeline Stability Revisited. The Journal of Pipeline Engineering, (4th Quarter):11.

[13] Det Norske Veritas (DNV) (2000); "Submarine Pipeline Systems, (OFFSHORE STANDARD DNV-OS-F101), Det Norske Veritas AS, January 2000.

[14] American Gas Association (AGA), (2002). Submarine Pipeline On-Bottom Stability - Levels 1, 2 and 3 Manuals (PR-178-01132). Pipeline Research Council International (PRCI), Houston, Texas, 2002.

[15] Ryan, J., Campbell, D., White, D., and Jas, E., (2011), A Fluid Pipe-Soil Approach to Stability Design of Submarine Pipelines, Proceeding of the $30^{\text {th }}$ Offshore Technology Conference (OTC), Houston, Texas., 2011.

[16] Lammert, W. F., Hale, J. R., and Jacobsen, V. (1989). Improved Basis for Static Stability Analysis and Design of Marine Pipelines. Proceedings of the Offshore Technology Conference (OTC), Houston, Texas, 1989.

[17] Pierson, Willard J., Jr. and Moskowitz, Lionel A. (1964); "Proposed Spectral Form for Fully Developed Wind Seas Based on the Similarity Theory of S. A. Kitaigorodskii" Journal of Geophysical Research, Vol. 69, p.5181-5190, 1964.

[18] Mathsoft, (2002), MathCAD ${ }^{\circledR} 11$ - User's Guide, Mathsoft Engineering and Education Inc., 101 Main Street, Cambridge, MA, USA.

[19] Jothi-shankar, M., and Sundar, V., (1980), Wave Forces on Offshore Pipelines, Proceedings of the $17^{\text {th }}$ International Conference on Coastal Engineering, Sydney, Australia, 1980. 